40. Ancyloxypha numitor, Fabr. Not abundant, but more so than at the north.

4I. Pamphila campestris, Bdv. Not common.

42. P. phylaeus, Dru. One of our most common species.

43. P. cernes, Edw. Abundant.

44. P. accius, S. and A. Abundant.

45. P. pontiac, Edw. Not common.
46. P. eufala, Edw. Not common.

47. P. fusca, G. and R. Rare.

48. Pyrgus tessellata, Scudd. A very common species.

49. Nisoniades juvenalis, Fab. Common. 50. Pholisora catullus, Fabr. Common.

5I. Eudamus pylades, Scudd. Common.

52. E. bathyllus, S. \& A. Very common.

53. E. tityrus, Fab. Common.

\title{
NOTES ON THE REARING OF PLATYSAMIA CECROPIA.
}

\author{
BY KATHARINE W. HUSTON, ROXBURY, MASS.
}

In the summer of 1892 the writer received twenty-nine eggs laid on June 3oth by a Cecropia moth in captivity, in Roxbury, Mass. Thirteen of them were detached from the surface on which they had been deposited. On July I $3^{\text {th }}$ twenty-four eggs hatched, among them the thirteen just mentioned. Though the young larvae remained in the box with their egg-shells, and were carried in a satchel four hours without food, none of the shells were eaten.

One of the caterpillars died the next day, one was lost, and two were put into alcohol. Of the remaining twenty, all but one arrived at maturity after an exceedingly healthy life of six weeks and a half, during which they moulted four times. Two of them, however, when ready to spin, seemed unable to produce silk, and died. Seventeen made cocoons.

The larvae were reared in Bristol, Maine. The breeding cage was merely a pasteboard box covered with wire netting. All the caterpillars were kept in the same box. It stood in an open window, but not in the sun, and was thoroughly cleaned every day.

The caterpillars were fed on apple leaves, which were always dipped in water before being placed in the box. Only the young shoots of the trees were used, as these furnished a suitable series of leaves from the very young and tender to the mature. They were taken from trees of widely different varieties.

The newly hatched caterpillars were about three-sixteenths of an inch long. The body was black with six rows of yellowish brown bristles extending its whole length. In a few hours the bristles also became black. On the fourth day the minute tubercles at the base of the bristles showed a decided yellow color, and on the sixth the bodies were an olive brown. On the eighth day, after having eaten nothing for about eighteen hours, the caterpillars moulted.

The color of the new skin was Indian yellow; the head, tubercles, and bristles were black; and the feet were yellow. Between the tubercles were rows of small black spots. Four caterpillars were much darker than the others. In less than an hour after their moult the Indian yellow changed to olive brown, which in turn gave place to black. Their bodies afterwards showed a yellowish tinge but were easily distinguishable from the others.

The largest ones now measured five-eighths of an inch. A few ate their cast-off skins, but the majority showed no disposition to do so, and the same was true after each successive moult.

The second moult occurred on the thirteenth day, after a fast of twenty-four hours. 
The bodies and feet were now of a pale green. On the first five segments was an additional row of tubercles below the others. Of the two middle rows, all were yellow except those on the second and third segments, which were a bright coral red, and those on the first, which were light blue. All the other tubercles were light blue. The head was greenish yellow with a black stripe down each side. The average length of the caterpillars at this time was one and oneeighth inches, the largest measuring an inch and a half.

They moulted for the third time on the eighteenth day, having eaten nothing for the preceding forty-eight hours. The bodies were of a beautiful, clear, light blue on the back, changing to a pale green at the sides and under part. The coloring of the tubercles was the same as before. The black spots were fewer, smaller, and fainter. The head and the feet were pale green, the former marked with black at the sides. The greatest length was two and one-eighth inches, the average, an inch and a half.

On the twenty-seventh day the fourth and last moult took place. The caterpillars had not eaten for two days and a half. The skin was now entirely of a light green color, the black spots having disappeared. The two middle tubercles on the second and third segments were of a dull red with seven or eight very short black bristles; those on the fourth segment were orange-yellow, nearly as large as the red, and bore six bristles. On each of these tubercles was a row of black warts under the bristles.

When full-grown the caterpillars measured three inches and a half and were as thick as the forefinger. Two completed their growth in five weeks and a half; and on September first all the cocoons but one were either finished or partly made.

During the first eight days the caterpillars fed mostly at night and ate very little. Through the day they would lie motionless on the exposed surfaces of the leaves, in groups, for hours at a time. Just before the second moult they developed vigorous appetites which constantly increased in voracity, both day and night, until the end.

In eating, they always began at the edge of the leaf, sometimes cutting away the part between two veins till the midrib was reached, sometimes eating directly across the veins. When half of the blade had been eaten they would often devour the entire midrib before beginning on the other half. They drank greedily whenever wet leaves were given to them.

In long periods of rest the head was drawn under the second segment, but in short periods it was merely withdrawn into the first segment, while the thoracic feet still retained their hold of the edge of the leaf, so that feeding could be resumed without change of position.

There was great unanimity in their movements. It was rare to find even one feeding while the others were resting; and after lying motionless for some minutes they would begin simultaneously to eat again, as suddenly as at the touch of an electric button.

They were social in their habits from the beginning, and even when full-grown as many as nine would lie close together on one branch, the head of one perhaps resting on the body of another. 'Two would sometimes feed from the same part of a leaf, their heads touching every time they returned to the starting point. They never showed any of that irritation at contact with each other so common with some caterpillars, nor did they pay any attention to the touch of a finger either on the skin or the tubercles; but if an aphis, introduced into the box on a leaf, crawled over one of them, the caterpillar tried by writhings and twistings to rid itself of its visitor.

Touching the larvae with the finger was an experiment made when they were well grown. Otherwise they were not handled at all during their entire development. 
As late as August igth there was one caterpillar whose length was only one inch. It had moulted but twice; and, as its mouth parts seemed to be defective, it was put into alcohol. The number was thus reduced to nineteen.

On August 22nd the first cocoon was begun in a corner of the box, and on the $23^{\text {rd }}$ and 24 th two other corners were utilized in the same way. After this the remaining caterpillars were removed from the box as fast as they were ready to spin, and placed under more favorable conditions.

Two spinning places were provided. The first consisted of small branches of an appletree standing in the sockets of a board, the whole enclosed in cotton netting. In the other the branches stood in a pitcher of water, the mouth of the pitcher being covered with paper to prevent death by drowning. These branches were not enclosed in any covering, but in no case did the caterpillars try to wander away.

In selecting a place for its cocoon the caterpillar, holding to the twig by its anal feet, sought, by reaching out in all directions to the full length of its body, to find points of attachment for what may be called its guyropes. The spinning of these was done very deliberately and occupied several hours. When the cocoon had been roughly shaped out the caterpillar rested for three or four hours, its work afterwards progressing rapidly.

All the caterpillars enclosed by netting made use of it in beginning their cocoons, while the others used the leaves and paper within their reach; so that many of the cocoons were partly concealed by a covering of foreign substance. In one instance three were grouped close together, and eight others were arranged in pairs.

In some cases the silk, when first spun, was beautifully white and lustrous, changing after exposure to the air to a rich reddish brown; in others it had a brown tinge from the first.

It has already been stated that two of the full-fed caterpillars died. One of them spun a few threads on August 3 oth, and for the remaining four days of its life went through all the motions of attaching threads but without producing any more. The other died on the second day after it had selected a place for its cocoon. It produced no silk at all.

The cocoons were collected, put into a pasteboard box, and kept in a cold, dark closet until April roth, when they were taken into a warm room. A cage was made by enclosing a small, deep-seated north window with netting, and the cocoons were pinned to the window frame. The glass itself was covered with netting stretched tightly over it.

During a period of nineteen days beginning May 24th, sixteen moths emerged, seven being males, and nine females. Two of them did not succeed in fully expanding their wings; the others were perfect insects. The seventeenth cocoon was found to contain only a dead caterpillar.

A few of the moths were given the freedom of the cage for several days, in the course of which five hundred and ten eggs were laid by two females, one depositing two hundred and forty-six, the other two hundred and sixty-four. A majority of the eggs hatched.

It will be seen that the conditions under which these moths were reared differ in several respects from the conditions considered essential by some entomologists, who say that the larvae should be kept in a damp cellar up to the time of the first moult; that not more than two or three should live in the same cage for fear of contagious disease; and that the atmosphere in which the cocoons are kept through the winter should be moist as well as cold.

My experience is not sufficient to enable me to decide whether my larvae escaped death merely by a happy chance, or whether the conditions just quoted are non-essential in all cases. I am inclined, however, to the latter opinion, in view of the many unsuccessful attempts to rear the larvae even when those conditions have been complied with. 

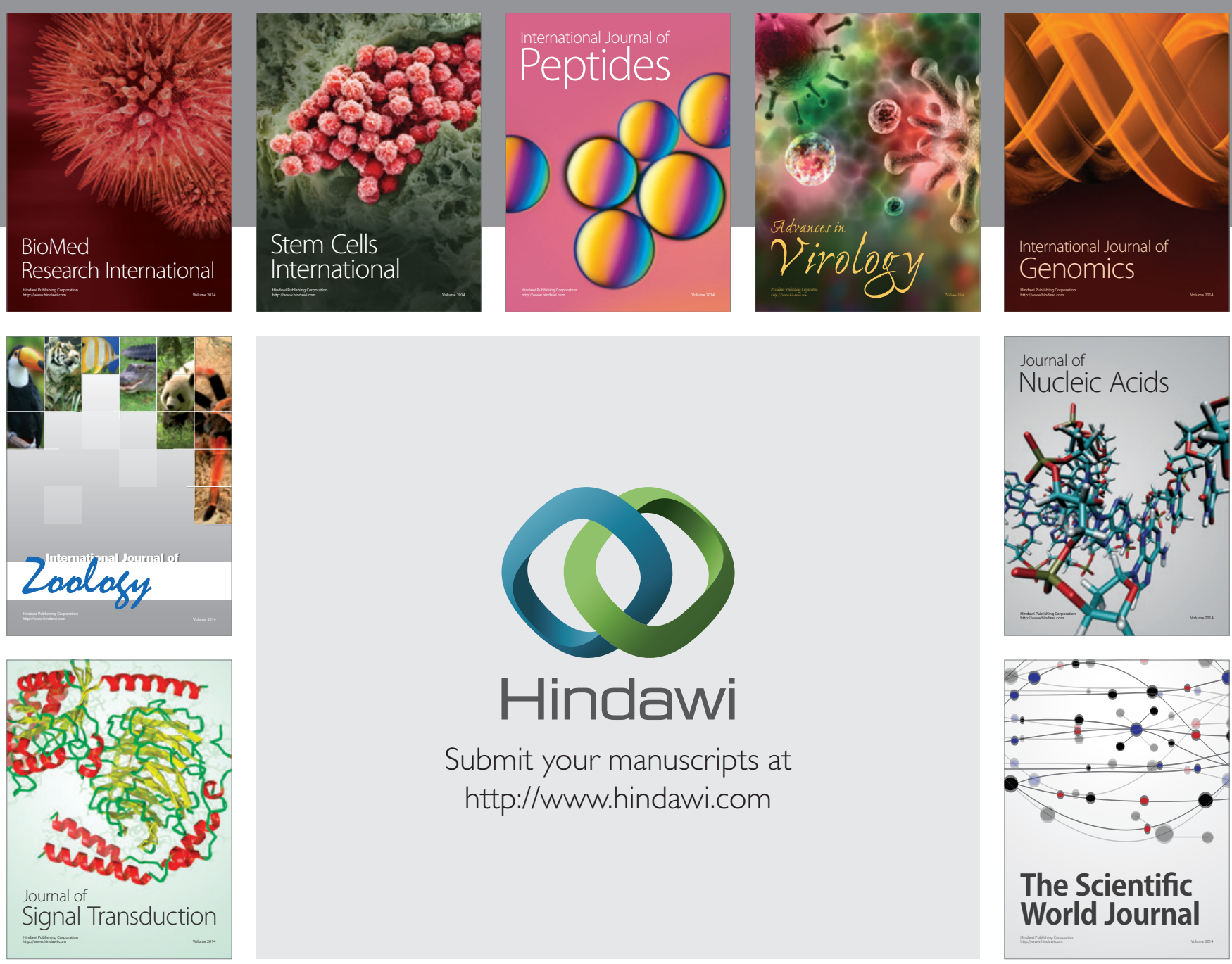

Submit your manuscripts at

http://www.hindawi.com
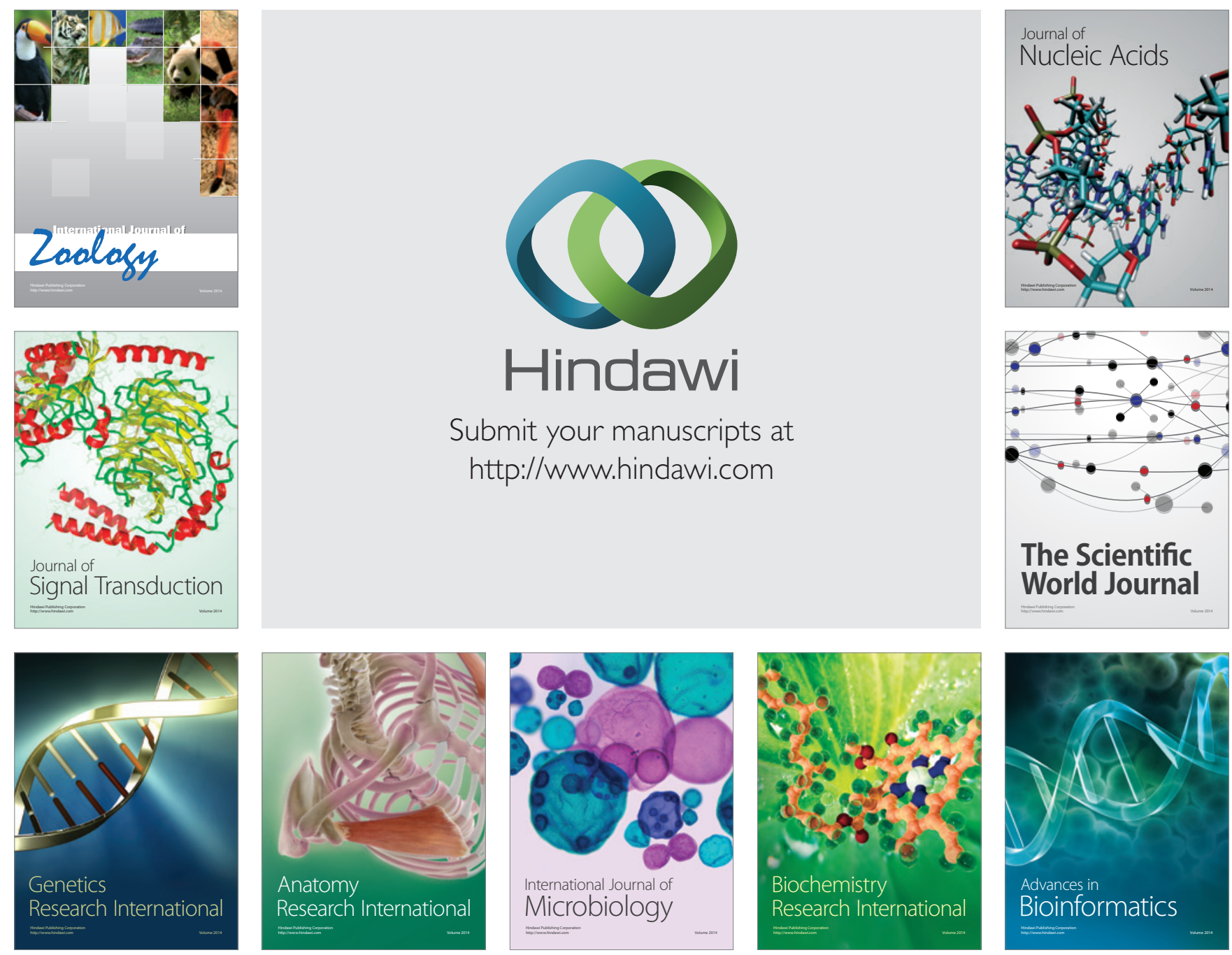

The Scientific World Journal
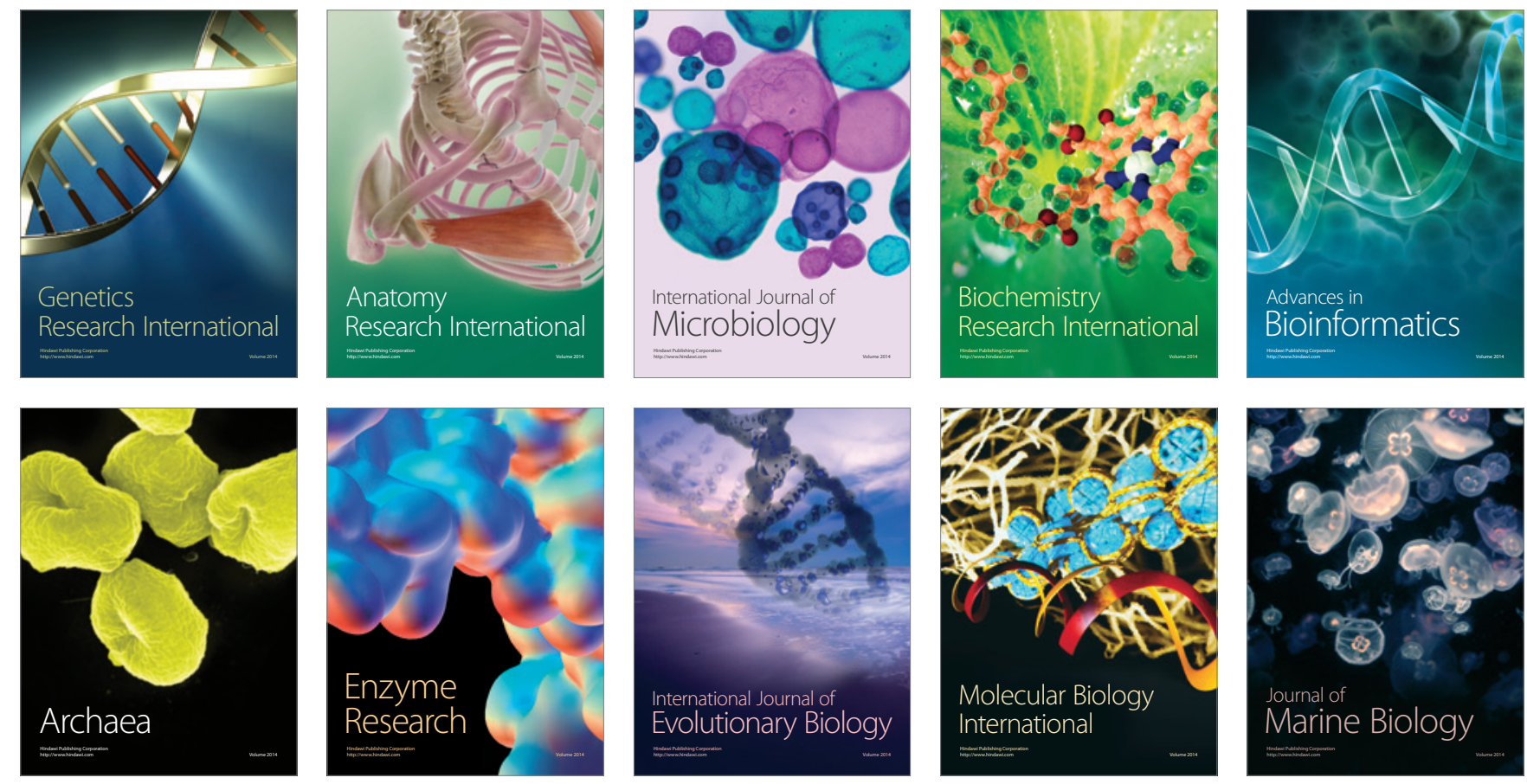